\title{
Kant e filosofia da diferença
}

\author{
Kant and the philosophy of difference
}

\section{Guilherme Almeida Ribeiro*}

Instituto Superior de Educação do Rio de Janeiro (ISERJ), Rio de Janeiro, RJ, Brasil

\section{Resumo}

Embora a filosofia de Kant não fosse requisitada diretamente por Gilles Deleuze para compor o "espaço aliado" de sua filosofia da diferença, é possível atentar para a valorização de certos elementos constitutivos da crítica kantiana no interior da démarche deleuziana. Conforme pretendemos demonstrar, os conceitos de Kant que são privilegiados por Deleuze estão implicitamente reunidos em torno do desdobramento de duas apropriações: em primeiro lugar, a recuperação sistemática da doutrina das faculdades como colaboradora de uma concepção de diferença não apenas empírica e externa, mas, sobretudo, transcendental e interna; e, em segundo lugar, a relação entre tempo e pensamento, ou melhor, a dessubordinação do tempo em relação ao movimento operada pela filosofia kantiana, a qual, inclusive, desloca as pretensões fundantes do cogito cartesiano.

Palavras-chave: Gilles Deleuze. História da Filosofia. Filosofia da Diferença. Immanuel Kant. Filosofia Francesa Contemporânea.

* GAR: Doutor em Filosofia, e-mail:guilhermealm@gmail.com 


\section{Abstract}

Although Kant's philosophy was not requested directly by Gilles Deleuze to compose the "allied space" of his philosophy of difference, we can note the valuation of certain constituent elements of the Kantian critique inside the deleuzian démarche. As we intend to demonstrate, the concepts from Kant who are privileged by Deleuze reside implicitly gathered around two appropriations: first, the systematic recovery of the doctrine of faculties as a collaborator of a conception of difference not only empirical and external, but especially transcendental and internal; and, secondly, the relationship between time and thought, or rather, the dessubordination time in relation to the movement operated by Kant philosophy which, including the founding claims moves the Cartesian cogito.

Keywords: Gilles Deleuze. History of Philosophy. Philosophy of Difference. Immanuel Kant. French Contemporary Philosophy.

\section{Introdução}

Gilles Deleuze afirmava que a história da filosofia é "totalmente desinteressante se não se propõe a despertar um conceito adormecido, relança-lo numa nova cena, ainda que ao preço de fazê-lo jogar contra ele mesmo" (DELEUZE \& GUATTARI, 2000, p. 109). Tal proposição parece cair como uma luva a respeito da leitura deleuziana do kantismo, visto que os elogios concedidos por Deleuze a Kant invariavelmente vêm acompanhados de sérias reservas de fundo ou de deslocamentos heterodoxos em relação aos objetivos originais. Para Deleuze, Kant foi o grande inventor e desbravador do domínio do transcendental - mas também seu primeiro traidor. Desse modo, se por um lado a filosofia da diferença de Deleuze é sensível à crítica kantiana ao Eu substancial, a qual seria um bom exemplo de análise das ilusões internas à razão contrastando com o mero elenco de erros externos ao exercício racional -, por outro lado, o pensador alemão não teria sido fiel a sua descoberta, na medida em que teria se apressado em decalcar as estruturas transcendentais a partir dos atos empíricos de uma consciência psicológica 
(DELEUZE, 1988, p. 224). Porém, mesmo quando critica Kant de modo mais incisivo, notadamente em Diferença e Repetição (1988), Deleuze reconhece na filosofia kantiana a genialidade de ter erigido o principio de finitude em princípio constituinte, rompendo radicalmente com um pensamento que desde o século XVII se projetava no infinito. Assim, segundo Deleuze, ao afirmar, por exemplo, uma diferença de natureza intransponível entre o domínio do espaço/tempo e o domínio do "eu penso", o kantismo abre uma fenda no cogito cartesiano bem antes de qualquer psicanálise.

Ainda que a filosofia de Kant não seja requisitada diretamente por Deleuze para compor seu "espaço aliado" (DELEUZE, 2007, p. 176), vale atentar para a valorização de certos atos noéticos constitutivos da crítica kantiana para o projeto de uma filosofia da diferença no interior da démarche deleuziana. Conforme veremos, pode-se dizer que os elementos conceituais kantianos privilegiados por Deleuze estão reunidos em torno do desdobramento explicativo de dois temas: em primeiro lugar, a recuperação sistemática da doutrina das faculdades como forma de apontar uma concepção de diferença não apenas empírica e externa, mas, sobretudo, transcendental e interna; e, em segundo lugar, a relação entre tempo e pensamento, ou melhor, a dessubordinação do tempo em relação ao movimento operado pela filosofia kantiana, a qual, inclusive, desloca as pretensões fundantes do cogito cartesiano.

\section{Doutrina das faculdades e diferença transcendental}

Deleuze considera que a originalidade da doutrina das faculdades, em Kant, consiste na determinação da forma superior de cada uma delas sem jamais as abstrair do horizonte da finitude humana, ao mesmo tempo em que a diferença de natureza entre as faculdades não é nunca suprimida: "Diz-se que uma faculdade tem uma forma superior quando encontra em si mesma a lei do seu próprio exercício (mesmo se dessa lei decorre uma relação necessária com uma das outras faculdades)" (DELEUZE, 1976, p. 14). Sob sua forma superior, uma faculdade é, pois, autônoma. O ponto de vista do conhecimento 
superior coloca em cena representações de dois tipos diferentes, a cada tipo correspondendo uma faculdade (definida como fonte específica de representações): a intuição, representação imediata que se relaciona com um objeto singular da experiência, tendo como fonte a sensibilidade; e o conceito, representação mediada, que tem por fonte o entendimento. Ao esmiuçar a atividade do entendimento na filosofia kantiana, Deleuze grifa o prefixo re, presente na ideia de representação, na medida em que este prefixo aponta o sentido de uma retomada ativa daquilo que se apresenta à sensibilidade. Desse modo, será possível conceber que sem a sensibilidade não há objeto dado, mas sem o entendimento nenhum objeto seria conhecido ou pensado.

Contudo, cumpre ainda verificar o papel, segundo Kant, de duas outras faculdades, a razão e a imaginação, nas sínteses do conhecimento. Quanto a isto, Deleuze cita oportunamente um trecho escrito por Kant na Dialética Transcendental: “a razão pura abandona tudo ao entendimento, e este se aplica imediatamente aos objetos da intuição, ou melhor, à síntese desses objetos na imaginação" (DELEUZE, 1976, p. 31). Portanto, neste caso, para Kant, o entendimento é a faculdade legisladora; os fenômenos não são submetidos à síntese da imaginação, mas submetidos por esta síntese ao entendimento legislador. Ao contrário do espaço e do tempo, as categorias constituem o objeto de uma dedução transcendental que visa simultaneamente colocar e resolver o problema da submissão dos fenômenos à legislação do entendimento. Segundo Deleuze:

Eis como, em suas linhas gerais, este problema é resolvido: $1^{\text {o }}$ Todos os fenômenos se dão no espaço e no tempo; $2^{\underline{0}}$ A síntese a priori da imaginação refere-se a priori ao espaço e ao tempo; $3^{\text {o }}$ Os fenômenos são, pois, necessariamente submetidos à unidade transcendental desta síntese e às categorias que a representam a priori. É neste sentido que o entendimento é legislador: não nos diz, certamente, a que leis estes ou aqueles fenômenos obedecem do ponto de vista de sua matéria, mas constitui as leis a que todos os fenômenos se submetem do ponto de vista de sua forma, de tal modo que "formam" uma Natureza sensível em geral (DELEUZE, 1976, p. 31). 
Deleuze enfatiza que, para Kant, não se deve confundir, na imaginação, a síntese com o esquema. $\mathrm{O}$ esquema pressupõe a síntese na medida em que esta é a determinação de um certo espaço e de um certo tempo, por meio dos quais a diversidade sensível é objetificada pelas categorias do entendimento. Mas, por outro lado, o esquema da imaginação é uma determinação espaço-temporal em que ela própria corresponde às categorias, em qualquer espaço e tempo possíveis, não se tratando aí da mera formação de uma imagem, mas da determinação de relações espaço-temporais que encarnam e realizam relações propriamente conceituais, sendo esta uma condição que torna possível a legislação do entendimento sobre as demais faculdades. Por isso, Deleuze observa e ressalta uma sutileza na ordem de desenvolvimento da primeira Crítica: na filosofia do conhecimento de Kant, o esquematismo da imaginação "não responde a pergunta: como os fenômenos são submetidos ao entendimento? Mas a esta outra: como o entendimento se aplica aos fenômenos que lhe são submetidos?" (DELEUZE, 1976, p. 32). A formulação deste problema kantiano dá testemunho da novidade que constitui o empreendimento da Crítica, pois, como observa Deleuze, "vê-se que em Kant fenômeno não quer dizer aparência, mas aparição" (DELEUZE, 1976, p. 18). A questão dos sistemas metafísicos clássicos, assim como o pano de fundo das querelas entre racionalistas e empiristas, são profundamente deslocados da busca pela definição essencial dos objetos para a interrogação das condições pelas quais eles aparecem para um sujeito, que se vê alçado ao horizonte possível de qualquer aparecimento.

Voltando ao papel da imaginação, é sabido que Kant nela reconhecia uma "arte oculta" tornando possível que relações espaço-temporais sejam perfeitamente adequadas a relações conceituais, apesar da diferença de natureza entre as duas fontes de representações, a sensibilidade e o entendimento. $\mathrm{O}$ que decerto nos traz dificuldades, pois deixa em aberto como é possível esta adequação. Deleuze, ao retomar tal dificuldade, opta por enfatizar o diagnóstico kantiano de que o esquematismo, ainda que não seja a arte mais profunda ou mais espontânea da faculdade imaginativa, é o ato original da imaginação, visto que só ela esquematiza "quando o entendimento se encarrega do interesse 
especulativo, quando se torna, portanto, determinante, então e só então a imaginação é determinada a esquematizar" (DELEUZE, 1976, p. 32).

Já no que concerne à razão, segundo Deleuze, o papel que apenas ela é capaz de realizar na arquitetônica kantiana seria duplo: ao mesmo tempo subjetivo e objetivo. Do ponto de vista subjetivo, as Ideias da Razão conferem um máximo de unidade e de extensão sistemática aos conceitos do entendimento. Privado do acordo com a razão, o entendimento não seria capaz de organizar em uma conclusão geral o conjunto das démarches relativas a um objeto. No interesse especulativo, a razão cumpre uma função original que é a da constituição de focos ideais da experiência, rumo ao quais convergem os conceitos do entendimento (máximo de unidade), formando perspectivas superiores que reflitam e abarquem tais conceitos (máximo de extensão). Ao descrever este papel subjetivo da razão nas sínteses do conhecimento, Deleuze é bastante claro ao citar ipsis literis um trecho da Dialética Transcendental onde Kant afirma:

A razão pura abandona tudo ao entendimento, que se aplica imediatamente aos objetos da intuição, ou melhor, à síntese desses objetos na imaginação. Ela se reserva somente à absoluta totalidade no uso dos conceitos do entendimento, e procura estender a unidade sintética concebida na categoria até o incondicional absoluto (KANT apud DELEUZE, 1976, p. 34).

Quanto ao ponto de vista objetivo desempenhado pela Razão, Deleuze observa que as Ideias da razão, embora não legislem sobre a matéria dos fenômenos, conferem uma unidade sistemática para a qual os objetos tendem, seja como problema ou como limite. "A razão é, pois, a faculdade que diz: tudo se passa como se..." (DELEUZE, 1976, p. 34). Não se trata de uma contradição em relação ao que foi dito acerca do ponto de vista subjetivo. Isto é, ao descrever o uso regulador das ideias, Kant não afirma em momento algum que a totalidade e a unidade das condições sejam dadas no objeto, mas, sim, que os objetos nos permitem tender para essa unidade sistemática de modo a constituir o mais elevado grau de nosso conhecimento, visto haver uma correspondência entre a matéria dos fenômenos e as ideias: 
A Ideia não é uma ficção, diz Kant; ela tem um valor objetivo, possui um objeto; mas esse objeto é ele próprio "indeterminado", "problemático". Indeterminada em seu objeto, determinável por analogia com os objetos da experiência, apresentando o ideal de uma determinação infinita em relação aos conceitos do entendimento: são esses os três aspectos da Ideia [para Kant]. A razão não se contenta, pois, em raciocinar em relação aos conceitos do entendimento. Ela "simboliza" em relação à matéria dos fenômenos (DELEUZE, 1976, p. 35) ${ }^{1}$.

Assim, em função do interesse especulativo, as faculdades ativas (imaginação, entendimento e razão) entram em um acordo a priori na formação do senso comum, não como um dado psicológico, mas como a condição subjetiva de toda "comunicabilidade", sem a qual o conhecimento não teria como pretender a universalidade (DELEUZE, 1976, p. 35). Em A Filosofia Crítica de Kant (1976), Deleuze não deixa de recorrentemente grifar esta que ele considera uma das originalidades do kantismo - e, também, de certo modo, o seu "calcanhar de Aquiles":

Um dos pontos mais originais do kantismo é a ideia de uma diferença de natureza entre nossas faculdades. Esta diferença de natureza não aparece somente entre a faculdade de conhecer, a faculdade de desejar e o sentimento de prazer e de dor, mas também entre as faculdades como fontes de representações. Sensibilidade e entendimento diferem em natureza, uma como faculdade de intuição, a outra, como faculdade de conceitos. Aqui ainda, Kant se opõe ao mesmo tempo ao dogmatismo e ao empirismo que, cada uma a sua maneira, afirmavam uma simples diferença de grau (seja diferença de clareza, a partir do entendimento; seja diferença de vivacidade, a partir da sensibilidade). Mas nesse caso, para explicar como a sensibilidade passiva entra em acordo com o entendimento ativo, Kant invoca a síntese e o esquematismo da imaginação que se aplica a priori às formas da sensibilidade em conformidade com os conceitos. Mas assim, o problema está apenas deslocado: pois a imaginação e o entendimento diferem eles mesmos em natureza, e o acordo entre essas duas faculdades ativas

Deleuze considera a "analogia", tal como descrita no "apêndice à Dialética" da CRP, um primeiro esboço da teoria do simbolismo que aparecerá na terceira crítica, a Crítica do Juízo. 
não é menos "misterioso". (da mesma forma, o acordo entendimentorazão) (DELEUZE, 1976, p. 36) ${ }^{2}$.

Com efeito, apontar a insuficiência da Crítica da razão pura em deduzir, sob a conformidade estrita do método transcendental, a harmonia oculta das faculdades não é um privilégio da leitura que Deleuze faz do texto kantiano. Vale lembrar que esta questão foi objeto de considerações contemporâneas à publicação das três Críticas, tendo lugar teorético de destaque na constituição de uma tradição de pensamento pós-kantiana que culminará no idealismo alemão e em seus esforços na busca por se determinar um princípio absoluto que permitisse deduzir a priori a totalidade do sistema.

\section{0 cogito e o tempo fora dos eixos}

Deleuze voltará a Kant em um curso que ministra sobre o filósofo, na Universidade de Vincennes em 1978. Na primeira aula, dirá: "Kant é como um trovão, deveremos sempre nos preparar [...] Inclusive eu terei de fazê-lo" (DELEUZE, 2008, p. 26). Não obstante seu afastamento crítico quanto a disposição, que considera por demais piedosa, da imagem do pensamento kantiana, alicerçada em cumplicidade aos pressupostos morais da representação - um tribunal da Razão erguido em sistema de julgamento por meio do uso comedido das faculdades (DELEUZE, 2007, p. 14) -Deleuze é profundamente respeitoso ao Acontecimento-Kant. Mais especificamente, "ao conjunto de criações e novidades que o kantismo trará à filosofia [...] em torno de um certo problema do tempo e de uma concepção completamente nova do tempo, uma concepção da qual pode se dizer que será decisiva para tudo o que irá se suceder depois" (DELEUZE, 2008, p. 20). Trata-se aí

2 Ainda segundo Deleuze, o problema da harmonia das faculdades é de tão modo importante para Kant que ele teria a tendência de interpretar a história da filosofia a partir dessa perspectiva, como evidenciaria a "Carta a Herz" de 26 de maio de 1789: "Estou persuadido de que Leibniz, com sua harmonia preestabelecida que ele estendia a tudo, não pensava na harmonia entre dois seres distintos, o ser sensível e o ser inteligível, mas numa harmonia entre duas faculdades de um só e único ser no qual sensibilidade e entendimento estão de acordo para um conhecimento da experiência". 
de conceber como Kant fornece à consciência moderna do tempo, em oposição a uma consciência antiga ou clássica do tempo, seu estatuto e expressão propriamente filosóficos. A questão é cara ao conjunto da obra deleuziana, conforme testemunha o fato de receber inúmeras tematizações em contextos dos mais variados, a exemplo do prefácio escrito para a publicação da tese de Éric Alliez, Tempos Capitais - relatos da conquista do tempo, orientada por Deleuze:

Há um horizonte provisório da viagem, que é o tempo kantiano: não como algo previsto, um objetivo, mas sim como uma linha que se vai descobrir no fim e da qual só se percebia, inicialmente, tal ou qual segmento furtivo. A pura linha do tempo que se tornou autônoma... O tempo livrou-se de sua dependência relativamente a todo movimento extensivo, que não é mais determinação de objeto, mas descrição do espaço, espaço de que se deve precisamente fazer abstração para descobrir o tempo como condição do ato. O tempo tampouco depende do movimento intensivo da alma; pelo contrário, é a produção intensiva de um grau de consciência no instante que depende do tempo. É com Kant que o tempo deixa de ser originário ou derivado, para tornar-se a pura forma de interioridade que vem escavar-nos, cindir-nos, à custa de uma vertigem, de uma oscilação que constitui o tempo: a síntese do tempo muda de sentido ao constitui-lo como a aberração intransponível (ALLIEZ, 1991, p. 15).

Com efeito, em Kant, sendo a apercepção transcendental a unidade formal da consciência pura, a qual se distingue de qualquer consciência empírica particular, abre-se uma rachadura no sujeito substancial da metafísica, alçado assim à categoria de ilusão transcendental. É o que permite a Deleuze evocar neste ponto a célebre fórmula de Rimbaud "Eu é um outro", na medida em que o eu passivo e intratemporal confere ao sujeito transcendental a função de um outro que o determina em sua unidade, devendo a atividade do sujeito transcendental se refletir no tempo para produzir um sujeito empírico, um eu-objeto dado à consciência. Tal como afirmara Kant, aludindo ao tempo da sensibilidade, "eu não posso me conhecer a mim mesmo como objeto do sentido interno, isto é, considerado como alma, a não ser como 
um simples fenômeno" (KANT, 1980, p. 30). Já no que concerne à inversão da subordinação do tempo ao movimento, Deleuze afirma que:

com Kant se produz uma novidade indescritível. É a primeira vez que o tempo se libera, se distende, deixa de ser um tempo cosmológico ou psicológico - pouco importa que se trate do mundo ou da alma - para devir um tempo formal, uma forma pura desdobrada. E isto será para o pensamento moderno um fenômeno de uma importância extrema. Será a primeira grande inversão kantiana na teoria do tempo (DELEUZE, 2008, p. 42).

A partir da ideia segundo a qual o tempo consiste em uma das formas puras da intuição sensível (a outra, como vimos, é o espaço), ele é introduzido na subjetividade transcendental e, consequentemente, se torna independente do movimento. Mais que isso, torna-se a condição de tudo aquilo que se move e muda no sensível. Deleuze toma de empréstimo uma fórmula poética de Hamlet de Shakespeare para expressar essa emancipação: o tempo está fora dos eixos, ou seja, ele está fora das marcações do movimento circular cardinal.

Se o tempo é condição de possibilidade da intuição empírica do objeto espaciotemporal ou fenômeno, ou seja, se o tempo (como o espaço) é aquilo que torna possível que as coisas se apresentem a nós conforme o modo como elas próprias aparecem, ele só pode ser uma intuição vazia, sem objeto. Tal como Kant afirma no item 3, parágrafo 14, de sua Dissertação de 1770: "Assim, a ideia do tempo é intuição e, porque é concebida antes de toda sensação, como condição das relações que se apresentam entre o que é sensível, é intuição, não proveniente dos sentidos [sensualis], mas pura" (KANT, 2005, p. 248, grifo do autor)

Um pouco mais à frente, precisamente no item 5 do mesmo texto, Kant afirma:

O tempo não é algo objetivo e real, nem substância, nem acidente, nem relação, mas é condição subjetiva, necessária pela natureza da mente humana, para coordenar entre si, segundo uma lei determinada, qualquer sensível, e é intuição pura. Pois coordenamos as substâncias bem como os acidentes, tanto segundo a simultaneidade quanto segundo a sucessão, tão-somente pelo conceito de tempo; e, consequentemente, a 
noção deste é, como princípio da forma, anterior aos conceitos daqueles (KANT, 2005, p. 250, grifos do autor).

Resta determinar o que nos permite apreender um objeto como o mesmo se ele apresenta duas determinações contraditórias, a saber, simultaneidade (coexistência) e sucessão. A resposta de Kant é que representações conflitantes podem se dar no tempo, desde que ele as determine como sucessivas. Quer o objeto se desloque ou não, segundo Kant podemos reconhecê-lo justamente porque o tempo no qual ele se encontra não se move. Sendo ele uma grandeza infinita, o tempo apresenta-se em infinitos instantes sucessivos tal qual uma linha reta em um sentido único. É dessa imagem da linha reta infinita, por meio da qual Kant representa o tempo, que Deleuze extrai a ideia de um tempo emancipado das marcações cíclicas que o movimento lhe conferia. Com efeito, Kant afirma textualmente que:

É precisamente porque esta intuição interna não se apresenta como figura, [que] procuramos suprir essa falta por analogias e representamos a sequência do tempo por uma linha contínua, que se prolonga até ao infinito e cujas diversas partes constituem uma série que tem apenas uma dimensão (KANT, 1997, p. 73).

Desse modo, temos a partir de Kant uma ideia do tempo como condição formal, que fundamenta o modo de ordenação das representações no espírito, visto que ele tanto estabelece as relações de sucessão e de simultaneidade, bem como a relação do simultâneo com o sucessivo que constitui a apreensão da permanência dos objetos no tempo. A consciência que temos das representações dos sentidos externos na experiência somente é possível devido à forma do tempo e se é certo dizer que as minhas representações sucedem-se umas às outras, nem por isso o tempo é algo em si próprio ou uma propriedade inerente às coisas, mas isto significa apenas que temos consciência delas como fenômenos constituídos pela sucessão temporal, ou seja, segundo a forma do sentido interno. Como todas as representações, tanto dos fenômenos internos quanto dos externos, são determinações do espírito, 
elas pertencem ao estado interno e como o estado interno é disposto segundo as relações do tempo (intuição pura), se tem assim formada a noção do tempo como forma universal de todo e qualquer o fenômeno. Há, portanto, um primado do tempo sobre o espaço no kantismo: o tempo é condição imediata dos fenômenos internos e, ainda, condição mediata dos fenômenos externos, pois estes últimos, mesmo sendo determinados a priori no espaço e conforme as relações espaciais, são representações e, como tais, têm que estar no tempo. Conforme adverte Deleuze a respeito desta primazia implícita do tempo sobre o espaço em Kant:

Seguramente a sucessão é temporal, porém isto não é mais que um modo do tempo, pois a coexistência e a simultaneidade pela qual se pretende definir o espaço é um outro modo do tempo, não é espaço. Trata-se de uma repartição muito ruim. $\mathrm{O}$ espaço não pode se definir como a ordem das coexistências, porque coexistência é uma noção que só pode ser compreendida em relação ao tempo: quer dizer literalmente “ao mesmo tempo" (DELEUZE, 2008, p. 42).

Vimos que o tempo, em Kant, se torna a forma de tudo o que se move e muda no sensível, sendo ele mesmo, contudo, a forma imutável do movimento e da mudança. Mas é importante não perder de vista que sendo o tempo a forma daquilo que é finito ele próprio não pode ser eterno. Segundo interpreta Deleuze, o fundamental aqui, em primeiro lugar, é retê-lo como a forma ou a condição que determina sucessivamente o movimento sensível, atentando para o fato de que ao se libertar do movimento circular e tornar-se unilinear e retilíneo, isto não significa, contudo, que o tempo seja propriamente definido pela sucessão, a qual é apenas um de seus modos. Sucessivas são as partes do movimento conforme determinado pelo tempo. Sucessão, bem como simultaneidade e permanência, constituem modos e relações temporais que ordenam nossas representações. Conforme argumenta Deleuze, "as coisas se sucedem em tempos diversos, mas são igualmente simultâneas ao mesmo tempo e permanecem num tempo qualquer. Já não se trata de definir o tempo pela sucessão, nem o espaço pela simultaneidade, nem a permanência pela eternidade" (DELEUZE, 
2011, p. 37). Desse modo, tempo e espaço ganham novas definições: o espaço como intuição que determina como os objetos distintos de nós nos afetam (forma do sentido externo) e o tempo como intuição que determina a relação das representações no nosso estado interno (forma do sentido interno). Mas é por meio do tempo, que esta interioridade é sempre reconfigurada. Pois, segundo Deleuze, na filosofia kantiana:

o tempo é a relação formal pela qual o espírito se afeta a si mesmo, ou a maneira pela qual somos interiormente afetados por nós mesmos. O tempo, portanto, poderá ser definido como o Afeto de si por si, ou pelo menos como a possibilidade formal de ser afetado por si mesmo (DELEUZE, 2011, p. 40).

Tem-se nesta noção do tempo, como forma da afecção de si, a chave de compreensão da quebra de identidade do Eu que Deleuze localiza na filosofia kantiana.

No § 16 da Analítica Transcendental, Kant define a apercepção pura como a autoconsciência que produz a representação Eu penso, a qual deve acompanhar as demais representações, sendo una e idêntica em toda a consciência. Kant denomina a unidade do Eu penso de unidade transcendental da autoconsciência, visto que é a partir dela que todo conhecimento a priori é possível. Neste sentido, segundo Kant, se as várias representações de uma dada intuição não estivessem necessariamente consoantes com a única condição que as permite estarem reunidas em uma autoconsciência geral não poderíamos considerá-las como nossas. Logo, a identidade total da apercepção de um diverso dado na intuição encerra uma síntese destas representações e somente se torna possível por intermédio da consciência de tal. Para Kant, a unidade sintética do diverso das intuições, na medida em que é dada a priori, é o princípio da identidade da própria apercepção, que precede todo o pensamento determinado. A ligação não está, contudo, nos objetos, nem tampouco pode ser extraída deles pela percepção, mas, pelo contrário, é uma operação do entendimento, o qual tem a função de ligar a priori e submeter o diverso das representações à unidade da apercepção. 
Antes de Kant, Descartes já havia reduzido o diverso dado a uma unidade formal, ao Eu penso, mesmo porque o conhecimento proveniente da experiência sensível é aí considerado confuso e duvidoso, sendo fonte inesgotável de erros. Sendo assim, na filosofia de Descartes, alcançar o verdadeiro implica rejeitar os objetos que são duvidosos e se ater sobre o domínio do pensamento que, imediatamente próximo à consciência, confunde-se com o próprio eu (donde seu caráter indubitável). Para Descartes, por serem imediatos, estes pensamentos se fundem na unidade do eu. Assim, se os pensamentos não são outra coisa que o Eu pensando, como ser pensante, eu sou uma coisa que pensa. Descartes preenche essa imediaticidade do pensamento com o próprio eu, ou seja, o pensamento que pensamos é, segundo Descartes, o nosso próprio eu no ato de pensar. A conclusão é conhecida: para Descartes, o Eu penso é a primeira verdade indubitável, o primeiro ato de conhecimento; tal é o Cogito, a única realidade (ou substância) que é imediatamente dada ao espírito, devendo as outras realidades serem deduzidas dele.

Segundo Deleuze, aquele que diz Eu, pela perspectiva cartesiana, recebe um valor lógico de determinação, enquanto princípio condicionante dos atos de conhecimento. Deleuze assim descreve o movimento lógico do Cogito cartesiano: "o eu penso é um ato de determinação instantânea, que implica uma existência indeterminada (eu sou) e que a determina como a de uma substância pensante (eu sou uma coisa que pensa)" (DELEUZE, 2011, p. 43). Entretanto, há uma objeção suscitada pela filosofia crítica de Kant que interessa a Deleuze. Encarando o Cogito cartesiano a partir de Kant, se pode interrogar, assim, como a determinação pode recair sobre o indeterminado se não se mostra sob que forma ele é determinável. Kant estabelece um domínio transcendental que muda a natureza dos pressupostos da dúvida de Descartes. Conforme reconstitui Deleuze em uma de suas aulas sobre Kant, ao dramatizar um diálogo entre personas cartesianas e kantianas:

O "eu penso" implica uma pura consciência de uma existência determinada. Até aqui, de acordo com Descartes, nenhum problema para ele. E é quando um filósofo não tem problemas que o filósofo seguinte está 
por chegar. Não há problemas para Descartes porque ele sustenta uma determinação, sustenta a posição de uma existência indeterminada. E dirá que a determinação - 'eu penso' - determina o indeterminado -' eu sou'. A determinação determina o indeterminado: sou uma coisa que pensa. Então diz Kant: "Não." É o nascimento da filosofia alemã. Penso em Leibniz. Há objeções que são como reprovações. Sob as objeções há sempre reprovações teoréticas. Já Leibniz dizia de Descartes: "Vai demasiado rápido". É como um juízo de gosto. Kant retoma algo disto: "é demasiado rápido". Diz: "de acordo, é uma determinação, de a determinação implica a posição de uma existência indeterminada, porém isto não me diz sob que forma esta existência indeterminada é determinável [...] Extrair a conclusão 'sou uma coisa que pensa' supõe - e você não tem o direito de supô-la - que a existência indeterminada é determinável como a de uma substância ou de uma coisa" (em latim, res cogitans, coisa pensante) (DELEUZE, 2008, p. 77)

Em suma, se "eu penso" é uma determinação que implica a este título numa existência indeterminada ("eu sou"), nem por isso sabemos como este indeterminado se torna determinável, nem, portanto, sob qual forma ele aparece como determinado. Com efeito, no parágrafo $\S 24$ da Analítica Transcendental, Kant levanta a questão de como o eu transcendental poderá se diferenciar do eu empírico que se intui e simultaneamente se identificar com ele em um mesmo sujeito. Como é possível a um sujeito pensante dizer que se conhece, uma vez que é dado na intuição do mesmo modo que os outros fenômenos? Em suma, como é possível sermos para nós mesmos objetos da intuição e das percepções internas? Tais perguntas expressam a dificuldade destacada por Kant quanto à possibilidade de nos intuirmos a nós mesmos interiormente. $\mathrm{O}$ desenvolvimento deste problema se dá no parágrafo $\S 25$ da Analítica, quando Kant afirma que, na medida em que precisamos, para nos conhecer, de uma intuição específica por meio da qual o diverso é dado, bem como da condução desse diverso à unidade da apercepção por meio de um ato do pensamento, a nossa existência não pode ser tratada como um fenômeno indeterminado ou menos ainda conforme uma mera aparência. No entanto, a determinação de nossa existência só se torna possível mediante a forma do sentido interno, ou seja, a forma como é dado no tempo o diverso ligado pela unidade sintética 
originária da apercepção (o "eu penso"). Por conseguinte, somente podemos nos conhecer como aparecemos a nós mesmos e não como somos em nós mesmos. Se para conhecermos um objeto exterior, isto é, que difere de nós, precisamos pensar um objeto em geral, bem como precisamos de uma intuição para determinar esse conceito geral (categoria), Kant afirma que isto vale também para o conhecimento de nós mesmos, ou seja, além de nos pensarmos, necessitamos de uma intuição do diverso em nós que determine essa consciência de si.

Desse modo, a espontaneidade da qual temos consciência no "eu penso" apenas pode ser concebida como a afecção de um eu passivo que sente o seu próprio pensamento, isto é, aquilo pelo qual ele diz " $E u$ " realiza-se nele e sobre ele - e não por ele. Portanto, diferentemente do que se passa na filosofia de Descartes, tal espontaneidade não pode ser concebida como atributo de um ser substancial.

Segundo Deleuze, o Eu (Moi) passivo, que Kant descreve por meio da receptividade da intuição, deve ser inserido no "eu penso" e, igualmente, no "eu sou". Em outras palavras, o tempo, a forma do determinável, deve ser interiorizada tanto pela determinação quanto pelo indeterminado. Com isso, o tempo passa a significar uma passividade no Eu (Moi, "receptivo e cambiante que representa para si tão somente a atividade de seu próprio pensamento") e uma rachadura no Eu (Je, "ato que determina ativamente minha existência"). É a passividade do Eu que explica a quebra e as paradas que ditam o ritmo da espontaneidade que caracteriza a atividade do Eu. É nesse sentido que Deleuze seleciona da crítica kantiana a Descartes a ideia de que a experiência do pensamento implica precisamente no reconhecimento dos elementos passivos os quais constituem a síntese do tempo. Isto é, o que Deleuze visa demonstrar é que a espontaneidade no pensamento não é absoluta, pois, ao ser inserida no pensamento, a forma pura do tempo traz consigo uma passividade e, portanto, uma diferença interna ao ato de pensar. Sendo a correlação do Eu passivo e do $E u$ rachado a própria descoberta do transcendental (e Kant, o filósofo moderno que formula explicitamente a exigência de se relacionar o tempo ao exercício do pensamento), Deleuze concluirá que: 
não é o tempo que nos é interior, ou ao menos ele não nos é especialmente interior, nós é que somos interiores ao tempo e, a esse título, sempre separados por ele daquilo que nos determina afetá-lo. A interioridade não para de nos escavar a nós mesmos, de nos cindir a nós mesmos, de nos duplicar, ainda que nossa unidade permaneça (DELEUZE, 2011, p. 45).

\section{Considerações finais}

Conforme comenta Éric Alliez, em que pese “a crítica a Kant introduzir uma dimensão nova na história da filosofia deleuziana, desenvolvendo uma função de contra-efetuação na qual se vem inscrever a posição problemática da modernidade" (ALLIEZ, 1991, p. 29), é fundamental lembrar que Kant recusa ao eu passivo qualquer poder de síntese, tomando a passividade enquanto mera receptividade sem síntese (abrindo caminho para a ressurreição prática da identidade do $E u$ na démarche kantiana por meio da primazia concedida às sínteses ativas do entendimento). É neste ponto que a fidelidade à descoberta kantiana exigirá que Deleuze se volte contra Kant: trata-se de aprofundar a estética transcendental para construí-la a um estatuto real e não apenas formal (o qual a condiciona na medida em que o sensível permanece ligado à forma a priori de sua representação), liberando o tempo agora não mais de sua subordinação ao movimento - tarefa já cumprida -, mas de sua submissão ao primado das categorias da consciência. Para citar novamente Alliez, em um arremate com o qual nos alinhamos: "reencontramos aqui a cronologia bergsoniana que margeia, a montante e a jusante, A filosofia crítica de Kant" (ALLIEZ, 1991, p. 29).

\section{Referências}

ALLIEZ, E. Tempos Capitais - relatos da conquista do tempo. Prefácio de Gilles Deleuze. Tradução de Maria Helena Rouanet. São Paulo: Siciliano, 1991. 
DELEUZE, G. Para ler Kant. Tradução de Sonia Dantas Pinto Guimarães. Rio de Janeiro: Francisco Alves, 1976.

DELEUZE, G. Diferença e repetição. Tradução de Luiz Orlandi e Roberto Machado. Rio de Janeiro: Graal, 1988.

DELEUZE, G. Conversações. Tradução de Peter Pál Pelbart. São Paulo: Ed. 34, 2007.

DELEUZE, G. Kant y el tempo (marzo/abril de 1978). Serie Clases. Buenos Aires: Cactus, 2008.

DELEUZE, G. “Sobre quatro fórmulas poéticas que poderiam resumir a filosofia kantiana”. Crítica e Clínica. Tradução de Peter Pál Pelbart. São Paulo, Ed. 34, 2011.

DELEUZE, G; GUATTARI, F. O que é a filosofia? Tradução de Bento Prado Jr. e Alberto Alonso Muñoz. São Paulo: Ed. 34, 2000.

KANT, I. Crítica da Razão Pura. Tradução de Manuela Pinto dos Santos e Alexandre Fradique Morujão. 4. Ed. Lisboa: Fundação Calouste Gulbenkian, 1997.

KANT, I. Escritos pré-críticos. Tradução de Jair Barbosa. São Paulo: Editora da UNESP, 2005.

Recebido: 21/03/2016

Received: 03/21/2016

Aprovado: 03/06/2016

Approved: 06/03/2016 